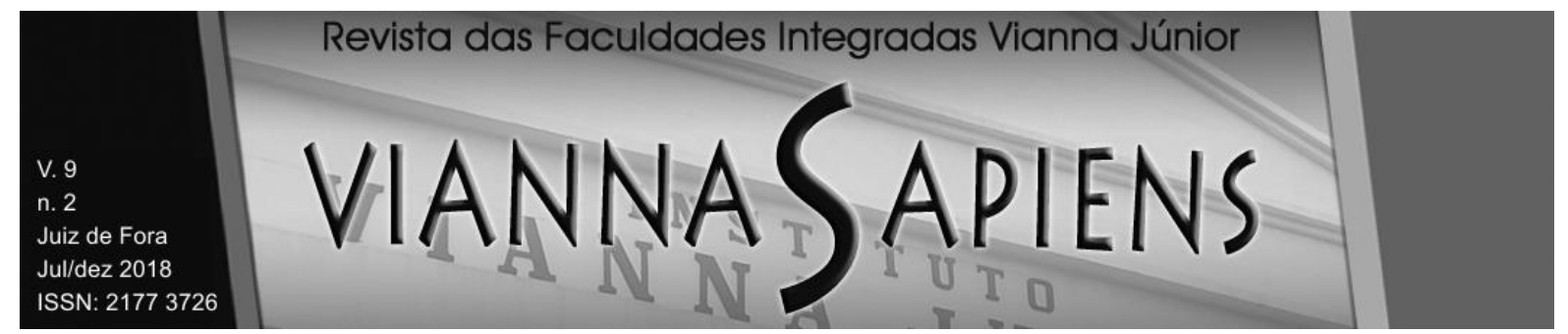

\title{
ANÁLISE DAS ESTRATÉGIAS COLABORATIVAS UTILIZADAS NO PROCESSO CRIATIVO NO SEGMENTO DE MODA
}

DOI: $10.31994 /$ rvs.v9i2.375

\author{
Deise Link ${ }^{1}$ \\ Dusan Schreiber ${ }^{2}$ \\ Margarete Fagundes Nunes ${ }^{3}$ \\ Serje Schmidt ${ }^{4}$
}

\section{RESUMO}

As estratégias colaborativas, que consistem da formação de alianças embasadas nas relações de confiança, representam, cada vez mais, uma alternativa para as organizações, notadamente daquelas de menor porte, para continuar operando no mercado. Por meio do estudo de caso único, em um empreendimento atuante no segmento de moda e design foi analisado o processo colaborativo com a cadeia de fornecimento. $\mathrm{O}$ estudo de caso evidenciou fragilidades no relacionamento entre a empresa brasileira e a italiana, que prejudicam com a estratégia colaborativa e não contribuem no processo criativo, subjacente ao desenvolvimento de coleções.

\section{PALAVRAS-CHAVE: ESTRATÉGIAS COLABORATIVAS. FORNECEDOR. CONFIANÇA.}

\footnotetext{
${ }^{1}$ Mestre em Indústria Criativa pela Universidade Feevale, https://orcid.org/0000-0002-9654-3653

2 Doutor em Administração pela UFRGS, https://orcid.org/0000-0003-4258-4780

${ }^{3}$ Doutora em Antropologia Social pela UFSC, https://orcid.org/0000-0003-2567-7643

${ }^{4}$ Doutor em Economia pela Universitat de Les Illes Balears, Espanha, doutorado em Administração na Unisinos https://orcid.org/0000-0002-5710-1828
} 


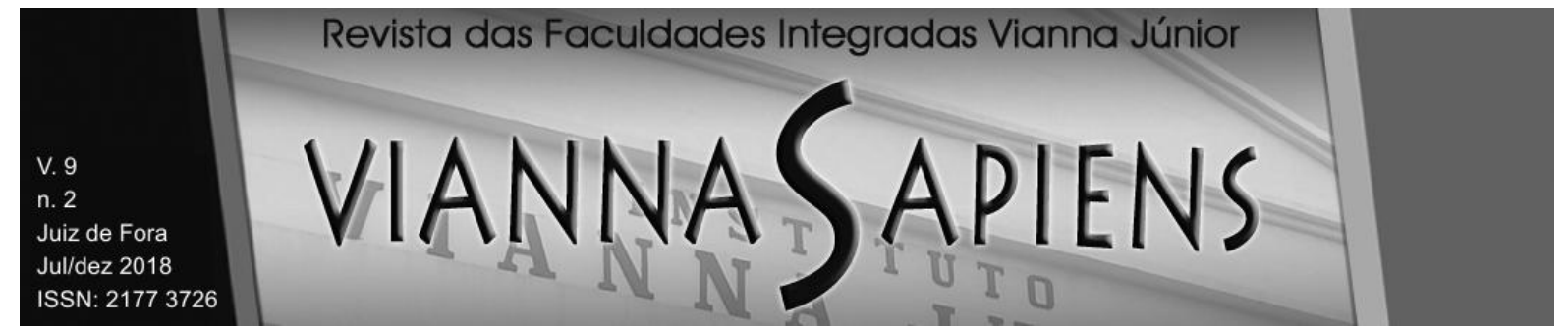

\title{
ANALYSIS OF COLLABORATIVE STRATEGIES USED IN THE CREATIVE PROCESS IN THE FASHION SEGMENT
}

\begin{abstract}
Collaborative strategies, which consist of the formation of alliances informed in trusts, represent, increasingly, an alternative for organizations, especially those of smaller, to continue operating in the market. Through the single case study in an active enterprise in the fashion segment and design was analyzed collaborative process with the supply chain. The case study showed weaknesses in the relationship between the Brazilian and Italian company that affect the collaborative strategy and does not contribute to the creative process underlying the development of collections.
\end{abstract}

KEYWORDS: COLLABORATIVE STRATEGIES. SUPPLIER. TRUST.

\section{INTRODUÇÃO}

As empresas buscam opções para se adequar a um mercado competitivo e globalizado. Nesta perspectiva a concorrência não é mais restrita às empresas de uma determinada região, independente de sua extensão territorial. Gradativamente os consumidores descobrem novas formas de acesso a diversas opções de produtos, sendo atraídos pela marca, diversidade, qualidade e alternativas de flexibilização de pagamento. Dentro deste cenário complexo, as organizações buscam alternativas para assegurar a sua competitividade e permanecer no 


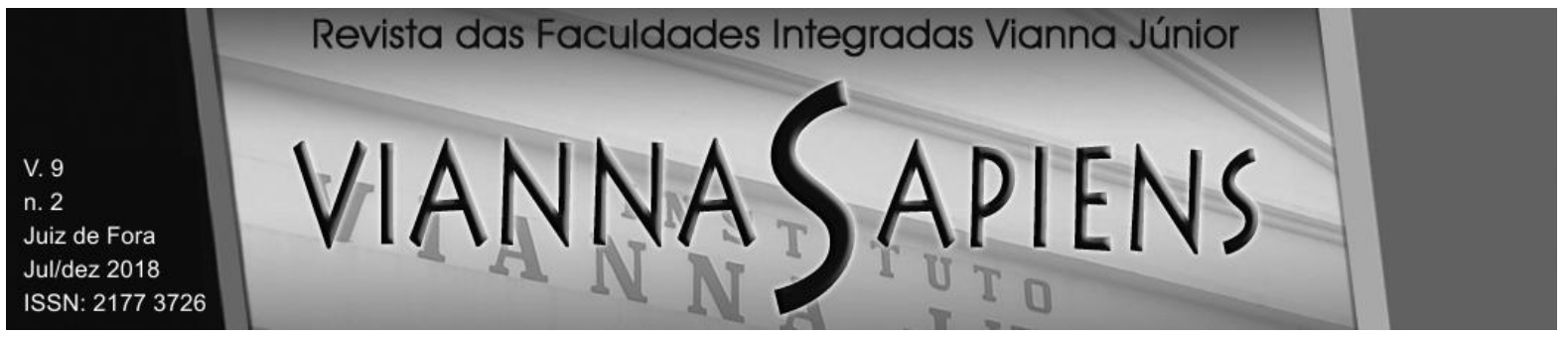

mercado. Dentre as quais destacam-se o uso de estratégias colaborativas, as quais serão abordadas na perspectiva do processo criativo.

Com o intuito de contribuir nesta temática, realizou-se uma pesquisa, cujos resultados foram utilizados para construir este artigo. $\mathrm{O}$ objetivo foi verificar quais foram as estratégias colaborativas utilizadas no processo criativo pela organização. A questão de pesquisa que norteou o desenvolvimento do trabalho foi: "Quais foram as contribuições das estratégias colaborativas para o processo criativo da organização X?".

A escolha do delineamento metodológico fundamentou-se em um estudo de caso único, com abordagem qualitativa, entrevistas com os responsáveis pela área de design e análise de narrativas. A empresa pesquisada é de médio porte localizada na região do Vale do Rio dos Sinos, prestadora de serviços de design de moda para empresas de grande porte de todo o Brasil.

O desenvolvimento da pesquisa foi fundamentado no pressuposto de que as estratégias colaborativas são construídas nas relações de confiança, na interdependência das partes e na inovação. O segundo pressuposto desta pesquisa sugere que a partir de um planejamento adequado com estratégias colaborativas implantadas e estabelecidas é possível obter maior sustentabilidade e rentabilidade resultando em uma fidelização dos clientes e qualidade nos desenvolvimentos dos materiais.

A estrutura do trabalho é constituída da revisão teórica, apresentada em tópicos que abordam e exploram a base conceitual acerca da estratégia colaborativa; a confiança, a interdependência das partes e a inovação. Após é detalhado o delineamento metodológico, onde são evidenciadas as etapas do processo de investigação adotadas pelos autores. Na sequência; apresentam-se os resultados, analisados à luz da revisão teórica, por meio de categorias analíticas que representam 0 alicerce do presente trabalho, descrevendo as estratégias 


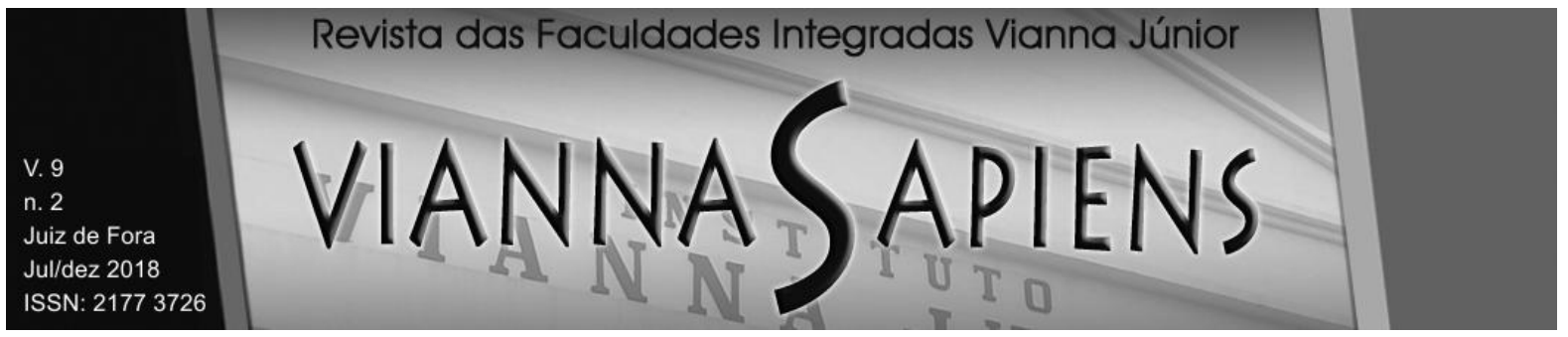

colaborativas utilizadas no processo criativo pela Empresa X. As contribuições finais e referências encerram o presente trabalho.

Para o desenvolvimento deste artigo utilizou-se a metodologia de estudo de caso, com a coleta de dados no modelo de triangulação, conforme indicado por Yin (2005), a saber: entrevistas em profundidade, realizadas com três gestores da empresa que mantêm relações com fornecedores, observação participante e levantamento documental. A primeira entrevista foi realizada com o responsável pela importação de materiais, o qual possui contato diário com este fornecedor; a segunda entrevista ocorreu com a responsável pela área de criação da empresa e a terceira entrevista foi realizada com a proprietária da empresa que concretizou a parceria com o fornecedor. Devido a vínculos e contatos em perspectivas diferentes dos três entrevistados na interação cliente-fornecedor, os elementos evidenciados, tanto por meio de entrevistas, como a partir do levantamento documental, mostraram-se suficientes para compreender as estratégias colaborativas no processo criativo.

A opção pelo estudo de caso foi julgada mais adequada, sob a perspectiva de alinhamento com o objetivo da pesquisa, à luz do delineamento metodológico de Gil (1996, p.122) "...é feito mediante o concurso dos mais diversos procedimentos. Os mais usuais são: observação, a análise de documentos, a entrevista e a história de vida". Ao encontro deste ponto de vista o artigo estrutura-se através da observação do processo criativo, entrevista com todos os indivíduos que contatam o fornecedor e leitura dos documentos elaborados para o processo criativo. Após a coleta de dados efetuou-se a sua análise (item descrito na sequência).

Corroborando com a perspectiva supra citada, Yin (2005) relata que, o estudo de caso é constituído de cinco elementos de pesquisa: "questões de estudo" (quem, onde e porque); "proposições de estudo (hipóteses, suposições que levaram ao estudo)"; "unidade de análise (quem possui estas evidências)"; "lógica que une 


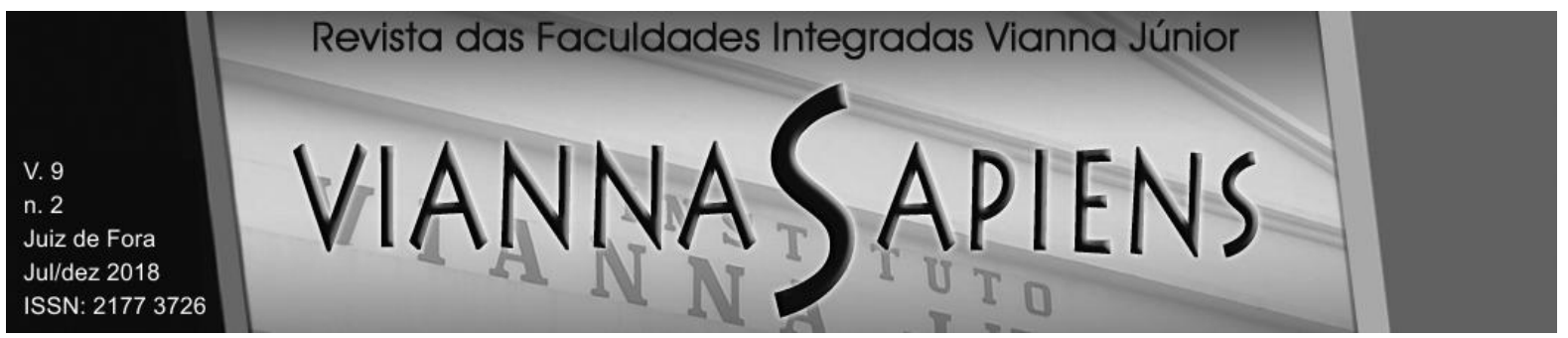

dados a proposições e interpretação dos critérios de constatação. Observa-se que todos os elementos citados por Yin estão contidos no decorrer deste artigo, validando a escolha metodológica.

Sumarizando, de acordo com suas características, a opção pelo delineamento metodológico, procedimentos na coleta de dados e análise dos mesmos, a pesquisa é considerada de natureza aplicada, descritiva e exploratória, de abordagem qualitativa.

A análise de conteúdo foi empregada para evidenciar aspectos relacionados com as categorias que emergiram por meio da revisão teórica, para a análise da estratégia colaborativa utilizou-se Dyer e Singh (1998); Gulati; Nohria e Zaheer;( 2000); Silva, Motta; Costa, (2007) ; Almeida, Silva e Júnior, (1998); Baum; Calabrase e Silverman, (2000); Ahuja, (2000) e Lira et al, (2007). Na sistemática de confiança e interdependência das partes apoiou-se no referencial teórico de Woolthuis, Hillebrand e Nooteboom, (2005); Barney; Hansen, (1994); Rousseau et al ,(1998); Zaheer et al, (1998); Zaheer, Venkatraman,(1995) ; Nooteboom (2007). Na perspectiva da aprendizagem os estudos realizaram a luz de Nonaka, (1994); Lane e Lubatkin (1998) Cohen e Levinthal (1990).

Cabe comentar que a empresa objeto de estudo está situada na região sul do Brasil, atendendo clientes de todo o país no segmento de moda, através da elaboração de acabamentos diferenciados para tecidos, couros e sintéticos. Desde o início de suas atividades a empresa $X$ possui um relacionamento próximo e consolidado, com este fornecedor. O processo criativo foi inserido somente alguns anos após a empresa $X$ se estabelecer no mercado, percebendo-se uma grande aceitação dos materiais desenvolvidos para os clientes da empresa $\mathrm{X}$. 


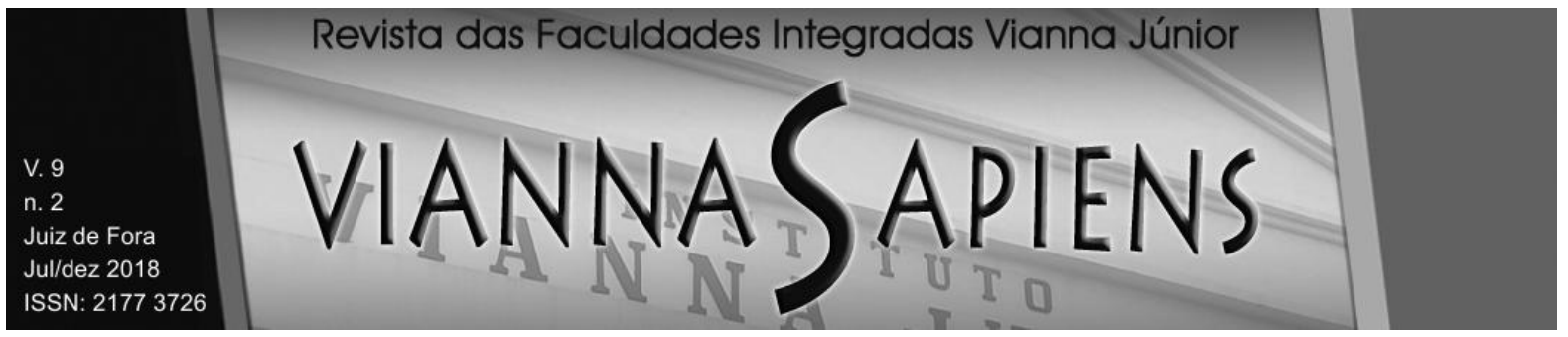

\section{ESTRATÉGIA COLABORATIVA}

A estratégia colaborativa compreende uma associação de agentes econômicos, que entendem que, por meio da colaboração, obtém benefícios como redução de custos, aumento de oportunidades de negócios, de faturamento e de lucro, através do desenvolvimento das vantagens competitivas. Este processo, segundo Dyer e Singh (1998), consiste, normalmente, na troca de informações e compartilhamento de rotinas de trabalho obtendo uma "partilha" de conhecimentos. Estes são combinados e recombinados com as informações das empresas envolvidas.

De acordo com Baum, Calabrase e Silverman (2000) as estratégias colaborativas constituídas por meio da formação de alianças com os fornecedores possibilitam para as empresas de pequeno porte ou aquelas que iniciaram sua operação recentemente, reduzir as dificuldades de cunho financeiro, pois faculta a negociação de preços, quantidades e prazos de pagamento. Portanto, as alianças podem ser consideradas uma forma das empresas de pequeno porte influenciarem o mercado. Segundo Ahuja (2000), através da troca de informações, da barganha por preços, possibilita-se 0 acesso a matérias primas e serviços com valores diferenciados e aprende-se novas habilidades.

Dyer e Singh (1998) exemplificam as alianças estratégicas através do caso da Nestlé e a Coca Cola que se associaram para distribuir bebidas quentes através de máquinas automáticas. Uma dominava a produção do produto e a outra a tecnologia para fazer a máquina, o resultado foi a ampliação da receita de ambas.

Conforme Silva, Motta e Costa, (2007) existe um conjunto de estratégias colaborativas adotadas pelas empresas de alto desempenho, em seus mercados específicos. O enfoque é o desenvolvimento de conhecimento com base em práticas organizacionais internalizadas e as especificidades de atuação no mercado. Incluem 


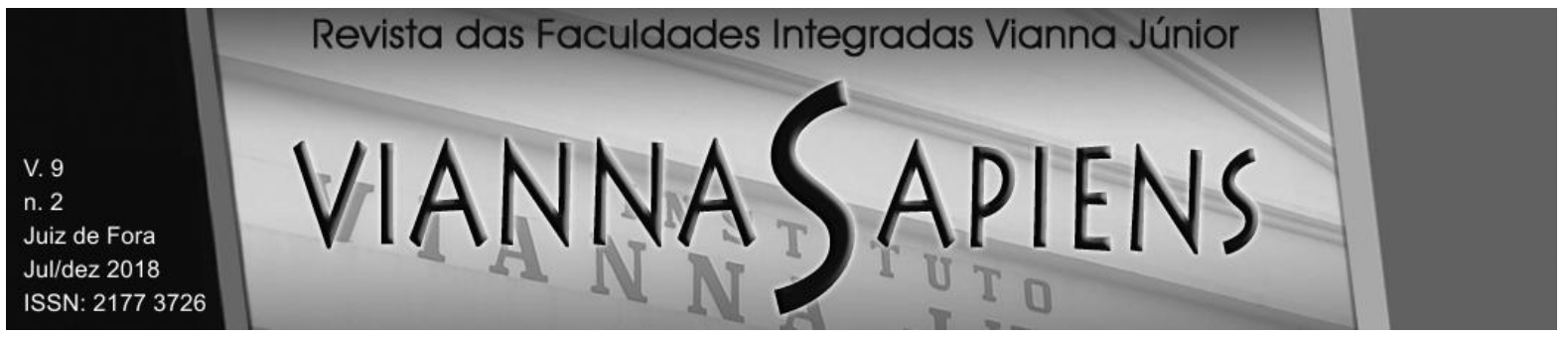

ainda: o compartilhamento do conhecimento subjacente ao know-how, aperfeiçoamento do talento gerencial, ou novas competências com outras empresas do mesmo segmento; redução do risco corporativo ao compartilhar elevados investimentos com outras empresas do mesmo segmento; acesso a novos clientes ou novos mercados em colaboração com os parceiros existentes; acesso a fatores de produção de baixo custo em colaboração com fornecedores; bem como o desenvolvimento de novas tecnologias de produtos ou processos em colaboração com universidades ou organizações de pesquisa sem fim lucrativo.

Outra possibilidade de estratégia colaborativa é o Licenciamento de tecnologia. Consiste na associação de duas ou mais organizações que visam a obtenção ou desenvolvimento de um determinado produto ou tecnologia. Estão subdividas em: Cross-contracting e Joint-ventures. Cross-contracting significa "o compartilhamento de tecnologias com outras empresas". As Joint-ventures de Tecnologia/Produto ou Marketing, por outro lado, visa a criação de uma nova entidade através da junção de empresas com o objetivo comum. Na maioria das vezes, é a criação de um novo produto, serviço ou novas tecnologias. Nesse caso ocorre, normalmente, o compartilhamento de patentes em tecnologia ou produtos, 0 que passa a ser denominado como conjunto de patente. Nesse processo também são firmados contratos de pesquisa, com a finalidade de compartilhamento da licença de inovações lançadas e implementadas, que podem resultar de contratos exclusivos (ou não), permutados por investimentos na pesquisa (originais ou adicionais) (SILVA, MOTTA; COSTA, 2007).

De acordo com Lira et al, (2007) em virtude do ambiente empresarial ser cada vez mais competitivo, as empresas formam parcerias e alianças estratégicas. Desta forma ampliam suas vantagens competitivas, mitigando os efeitos da competição acirrada. Três fatores que impulsionam a constituição das estratégias colaborativas: os integrantes continuam independentes após a formação da aliança; eles 


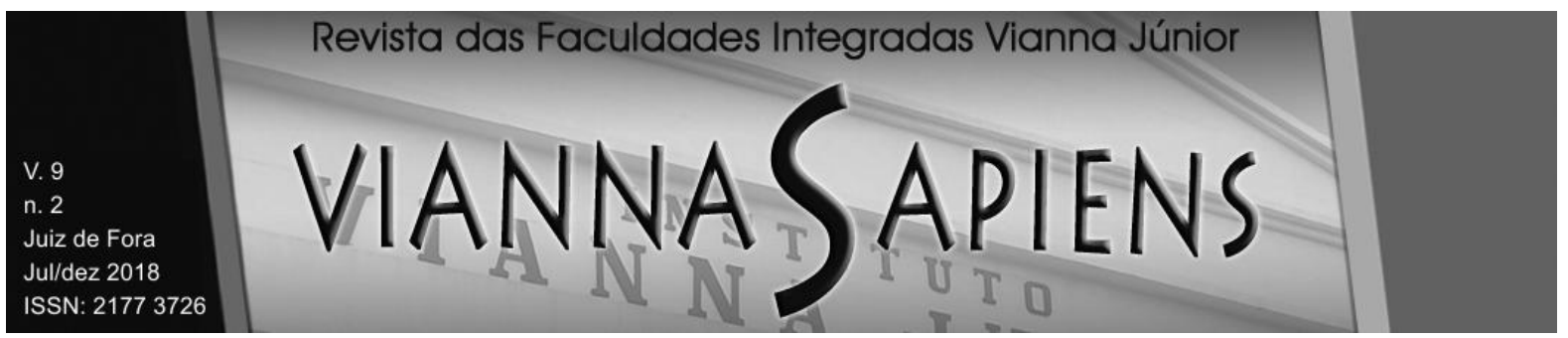

compartilham os benefícios e controle sobre o desempenho das tarefas; são responsáveis e contribuem constantemente na área da tecnologia, produtos e outras áreas estratégicas.

\section{A CONFIANÇA - A INTERDEPENDÊNCIA DAS PARTES}

Segundo Woolthuis, Hillebrand e Nooteboom (2005), a confiança pode ser definida como a expectativa do comportamento das partes envolvidas em uma determinada relação, ou seja, se elas agem e se comportam de maneira confiável, previsível e justa, principalmente em situações que podem favorecer a manifestação do oportunismo. Na percepção destes autores, a confiança reduz custos e aumenta a competitividade, tendo em vista que as empresas que possuem laços fortes favorecem a confiança, realizam as operações com mais agilidade e possuem menores custos de transação.

Woolthuis, Hillebrand e Nooteboom (2005) apresentam três perspectivas para o processo de confiança: a primeira é que a confiança estimula as partes envolvidas a desenvolver expectativas favoráveis na relação; a segunda perspectiva é a de que no meio de um processo de negociação podem surgir contingências impossíveis de serem previstas e/ou expressas contratualmente, portanto, quando existe a relação de confiança, reduz-se os riscos do oportunismo de qualquer uma das partes envolvidas. Já a terceira dimensão do construto de confianças refere-se "à complexidade das interações que compreendem os relacionamentos de negócios", pois existem situações que somente poderão ser superadas por meio de laços fortes entre os envolvidos (confiança).

São identificados três tipos de confiança nas trocas econômicas: confiança de laços fortes, confiança de laços semifortes e confiança de laços fracos. Barney e 


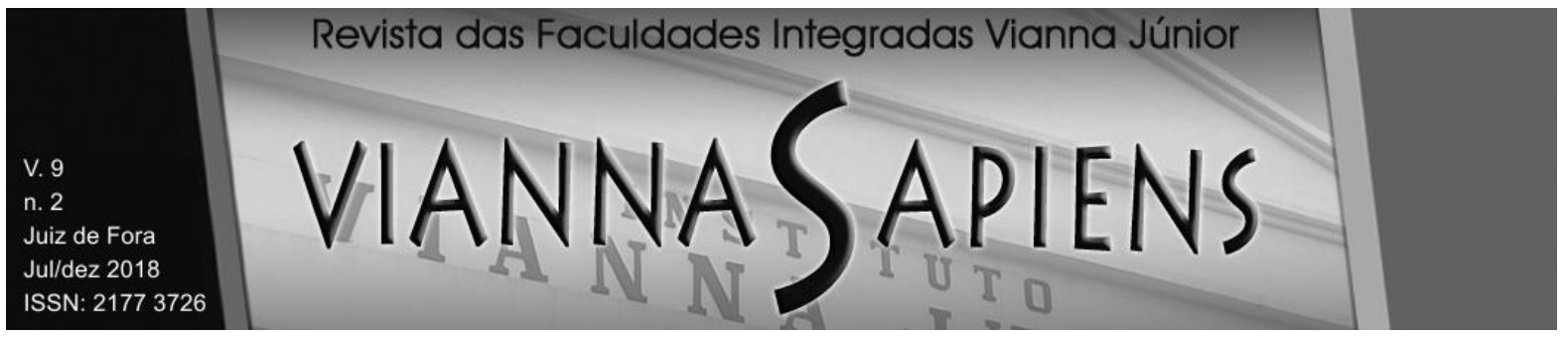

Hansen, (1994) argumentam que os laços fracos embasam uma relação de confiança, pois só pode ser uma fonte de vantagem competitiva quando os concorrentes investem em mecanismos de proteção e de transparência, como, por exemplo, a governança corporativa. Já a forma semiforte as relações de confiança pode ser uma fonte de vantagem competitiva quando concorrentes desenvolvem um conjunto de competências específicas, bem como de habilidades de governança de compartilhamento. Considera-se que o custo de imitação dessas habilidades seja mais elevado do que o benefício individual decorrente do comportamento oportunista. As condições de laços fortes de confiança, por outro lado, é naturalmente, a fonte de vantagem competitiva, pois geram menor custo de negociação na relação.

Segundo Rousseau et al (1998) a confiança propicia o surgimento de um comportamento cooperativo, promovendo alterações adaptáveis nas organizações, manifestadas, principalmente, por meio de formação de redes, redução de conflitos, gerando retornos eficazes em momentos de crise. A confiança inter organizacional faculta 0 estabelecimento das relações entre grupos organizacionais, que apresentam traços funcionais similares, pela convergência de interesses.

A confiança é fortalecida pelas pessoas envolvidas no referido processo relacional, ou seja, é a qualidade das relações pessoais que influencia, estimula ou desencoraja comportamentos oportunistas entre as empresas. Esta assertiva referese às influências de confiança interpessoal na troca econômica, que caracterizam os sistemas sociais complexos (exemplo: empresas ou organizações). No entanto, a perspectiva de troca relacional não estipula mecanismos pelos quais a ação de nível individual afeta os resultados de nível organizacional (ZAHEER et al, 1998)

A pesquisa realizada por Barney e Hansen (1994) evidencia o que é positivo e vantajoso para estabelecer e consolidar as relações de confiança interfirmas, destacando a redução dos custos de transação, a mitigação do comportamento 


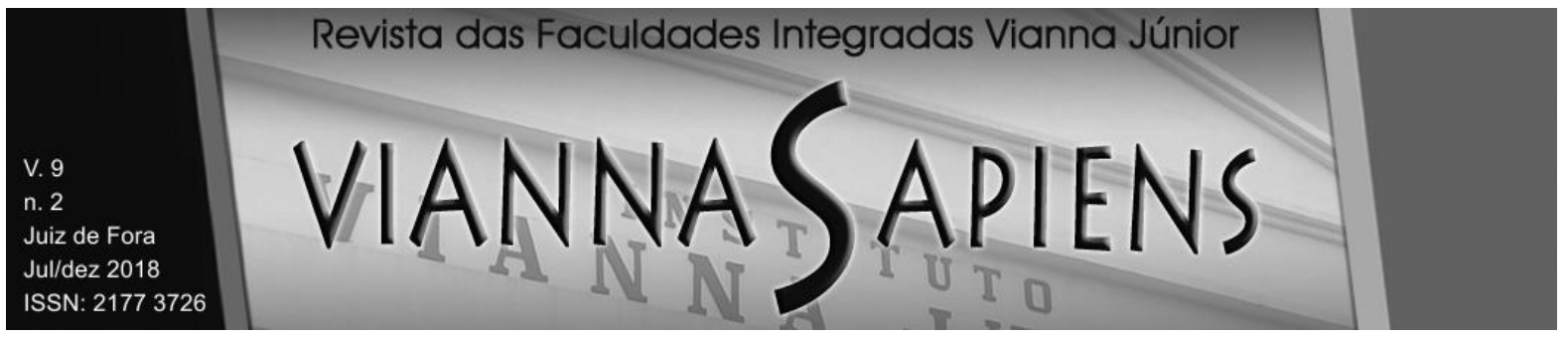

oportunista e o controle dos custos de transação de troca, obtendo como resultado uma governança mais eficiente. Em outra perspectiva, Nooteboom (2007) apresenta que a relação de confiança entre pessoas e a confiança nas organizações vai depender das posições e dos papéis que elas possuem na organização e o modo acordado entre elas para coordenar o comportamento da empresa e das pessoas.

A confiança nas intenções é abordada pelo Nooteboom (2007) como a ausência de oportunismo, ou ainda, a presença de benevolência, boa vontade e solidariedade. A confiança técnica é a capacidade de estar em conformidade com as expectativas estabelecidas na negociação cumprindo com os compromissos assumidos sem contratempos. O indivíduo precisa ser confiável, isto é, passar segurança neste processo, demonstrando possuir o conhecimento ao realizar o processo de negociação fornecendo todas as informações necessárias.

Segundo Nooteboom, (2007) a consolidação da relação de confiança dependerá de determinadas circunstâncias, ou seja, significa que ela é limitada. Algumas situações podem surgir que vão além da competência, comprometendo a confiança tais como: situações econômicas locais, pressões do mercado, falta de atenção e suporte à confiabilidade e credibilidade correndo o risco de rompimento implicando na fragilização da relação e na disseminação da imagem negativa desta empresa no mercado.

\section{APRENDIZAGEM}

De acordo com Nonaka (1994) a aprendizagem é comumente percebida como um processo bidimensional: a primeira dimensão consiste do conhecimento tácito e a segunda do conhecimento explícito. Enquanto que por conhecimento explícito entende-se todo o conhecimento transmitido formalmente, com uma 


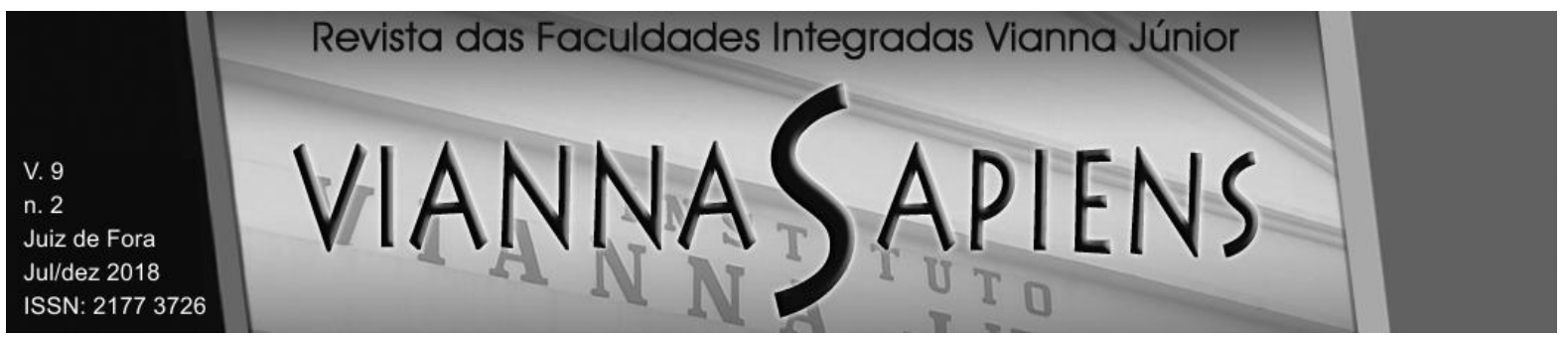

linguagem sistemática, já o conhecimento tácito é decorrente da experiência e vivência do indivíduo, o qual, devido a esta característica intrínseca, é considerado difícil de ser ensinado. Este conhecimento está vinculado aos elementos cognitivos e técnicos.

Cooperando na perspectiva dos elementos cognitivos e técnicos, os indivíduos se utilizam de modelos mentais subjacentes aos modelos de trabalho, com base na criação e manipulação de analogias em suas mentes. São incluídos diversos mecanismos de assimilação, tais como, esquema de cores, paradigmas, crenças e pontos de vista. De acordo com Johnson e Laird (1983 apud NONAKA, 1994), o conhecimento tácito é aquele que envolve ações sólidas de conhecimento, vinculado a atividades laborais, tais como artesanato, além do desenvolvimento e internalização de capacidades individuais, em contextos específicos.

Desta forma, o processo de aprendizagem na organização ocorre por meio de troca contínua entre o conhecimento tácito e explícito. Neste ambiente há um conjunto de interações que suscitam a aprendizagem, decorrentes da formação de alianças ou outsourcing com clientes, fornecedores, distribuidores ou ainda com a própria concorrência. Formaliza-se o escopo e objeto de trabalho, bem como as definições de restrições das partes. Os conhecimentos obtidos deste "escopo contratual" podem ser transmitidos através da socialização por observação, imitação e prática. Emprega-se comumente reuniões, conversas informais ou outros mecanismos que facultam a disseminação e internalização deste novo conhecimento.

Corroborando esta perspectiva, Lane e Lubatkin (1998) assinalam que a capacidade de absorção do conhecimento entre as empresas ocorre na relação entre a empresa "professor" e a empresa "aluno". A intensidade de troca de conhecimento ou aprendizagem advém das seguintes condições: o nível de abertura da "empresa professor" em repassar o conhecimento, com a condição sine qua non, 


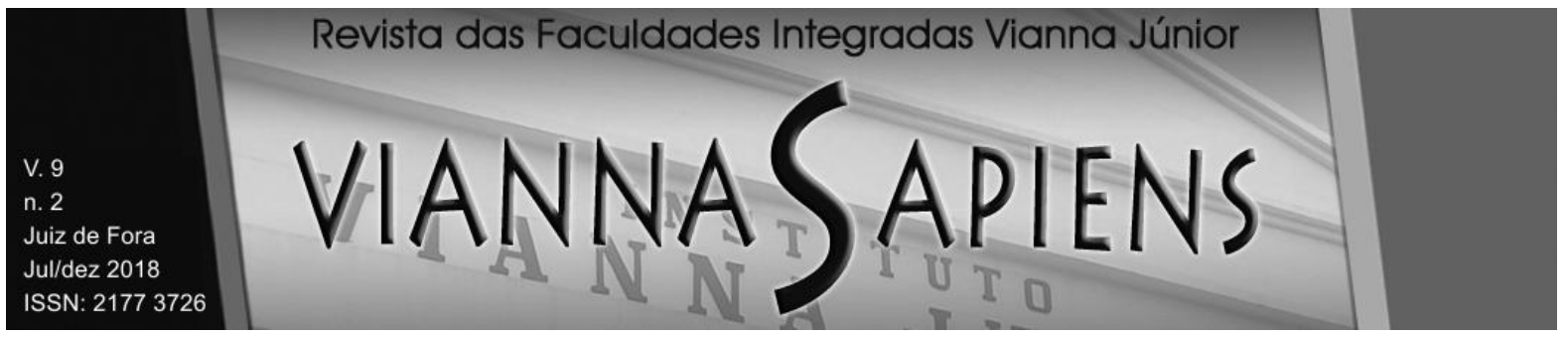

da similaridade da base do conhecimento preexistente nas empresas, bem como das práticas e estruturas organizacionais. Leva-se em conta, ainda, o histórico vivenciado pelas empresas, os recursos disponíveis, o conhecimento prévio adquirido e o perfil das lideranças.

O conhecimento é absorvido de maneira mais rápida e assertiva, quando associado aos conhecimentos e estruturas já existentes. Na perspectiva de Lane e Lubatkin (1998) as empresas que possuem elevados níveis de conhecimento investem, habitualmente, um valor superior ao investido por empresas concorrentes, em atividades da área de pesquisa e desenvolvimento, formando alianças voltadas para a tecnologia, com mais eficiência e eficácia.

$\mathrm{O}$ aprendizado deve ser condizente com a estrutura e suporte da empresa que está recebendo esta demanda do conhecimento, para não frustrar e gerar descontentamento entre os envolvidos. Em contrapartida, se este conhecimento for vinculado a uma área de atuação na qual a empresa destaca-se e possui experiência relevante, este poderá ser comercializado entre as demais empresas que vierem a se interessar pelo mesmo. Lane e Lubatkin (1998) elucidam que para receber este aprendizado é importante saber lidar tanto com diversidade, bem como com a similaridade do conhecimento, que estas empresas apresentam (empresa aluno e empresa professor) na base do seu conhecimento, seja ele técnico, científico, acadêmico ou, ainda, seu know-how, pois o conhecimento apreendido evolui em habilidade para a organização, facultando destacá-la no mercado em que atua.

Cohen e Levinthal (1990) complementam que o conhecimento será absorvido por uma empresa se o mesmo estiver relacionado com os conhecimentos adquiridos anteriormente. $\mathrm{Na}$ área cognitiva dos indivíduos, o aprendizado assimilado faculta o armazenamento das informações com maior facilidade devido à associação da informação nova com os conhecimentos preexistentes. Desta forma, a 


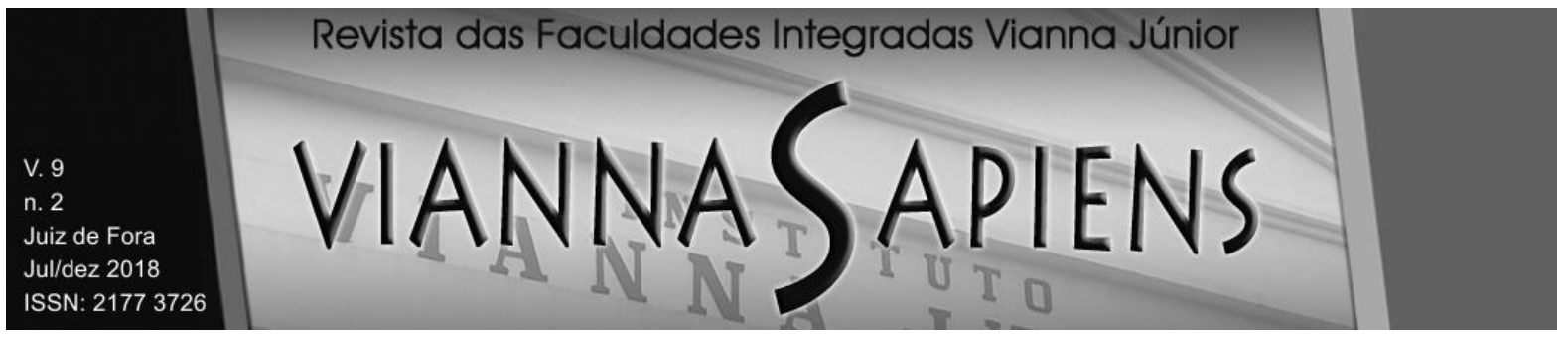

aprendizagem ocorre de forma cumulativa; quanto maior for o conhecimento prévio, maior o domínio do aprendizado futuro. Visto que a aprendizagem é a base para a inovação, é possível afirmar que esta ocorrerá apenas se construída de forma gradativa.

O processo de aprendizado na área de pesquisa e desenvolvimento, bem como a absorção de novos conhecimentos se dará pelas exigências do mercado e dos consumidores, associados a esta demanda, desde que apresentem a capacidade de apropriabilidade e condições de oportunidades tecnológicas. A demanda refere-se ao volume de vendas que este item terá, bem como a elasticidade do preço em relação a demanda (quanto o mercado paga por este produto). A apropriabilidade refere-se ao nível de competência que a empresa possui para obter o lucro decorrente desta atividade de inovação comentado por Cohen e Levinthal (1990) e Nonaka(1994).

\section{ANÁLISE E DISCUSSÃO DOS RESULTADOS}

A empresa, objeto de estudo, está inserida no segmento de moda, vinculada ao vestuário, criando efeitos e texturas de acordo com as demandas dos clientes para couro, tecido e sintético. Ela desenvolve pesquisas de tendências e cria produtos "conceitos" para cada estação. Seus clientes estão presentes em todo Brasil. Neste segmento, a disputa por preços e produtos que estejam adequados às necessidades dos clientes é fundamental para se manter no mercado. Neste contexto, os produtos asiáticos são uma das opções de produtos concorrentes com preços muito abaixo dos praticados, tornando o segmento mais exigente e em busca de preços acessíveis. 


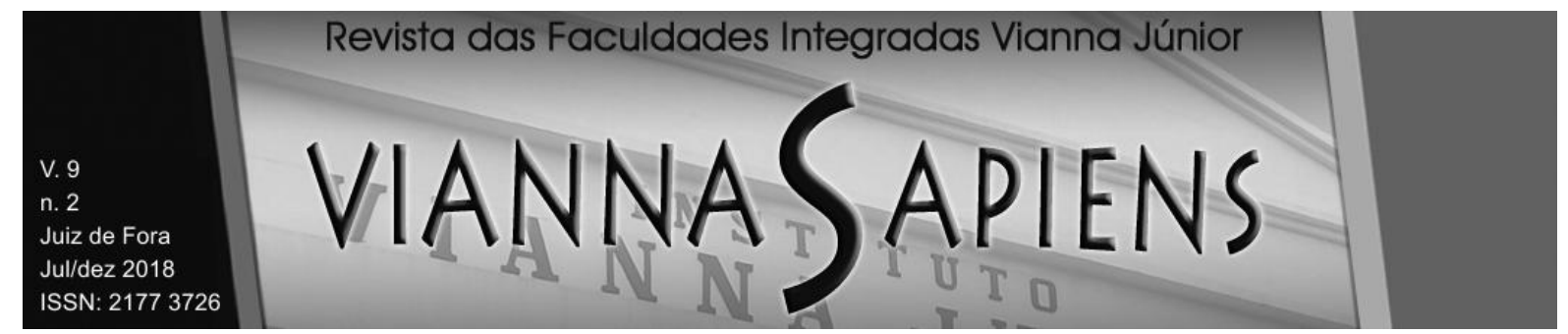

Uma alternativa para amenizar este mercado é o de estabelecer uma estratégia colaborativa com os clientes e fornecedores, com características similares ao do modelo teórico apresentado por Almeida, Silva e Júnior (1998) e por Dyer e Singh (1998). Ou seja, através da troca de informações previstas em contratos mais longos foi possível perceber que as partes envolvidas adquiriram mais conhecimento subjacente ao processo operacional, em alinhamento com as necessidades deste mercado. Dentro desta perspectiva, a análise dos dados empíricos com as vertentes teóricas revisadas foi realizada, possibilitando elucidar as estratégias colaborativas, a confiança, a interdependência das partes e a aprendizagem. A estratégia colaborativa desenvolvida pela empresa com seu fornecedor, evidenciou troca de informações, aquisição de máquinas com tecnologia de ponta, treinamento e aprendizado da empresa $X$. A finalidade destas ações foi de promover um processo de fortalecimento das empresas envolvidas. Com a troca de informação foi possível estreitar laços e gerar o conhecimento e a qualidade no processo.

A entrevista realizada com o responsável na empresa $X$, pelo contato direto com o fornecedor, objetivou verificar a existência de um processo colaborativo, como o descrito por Dyer e Singh (1998), no qual as partes envolvidas se utilizam da parceria para gerar renda, desenvolvendo vantagens competitivas, bem como identificar se as estratégias colaborativas praticadas resultam em um desempenho superior com geração de know-how, talento gerencial ou novas competências, como o descrito por Silva, Motta e Costa (2007). Este tipo de interação deveria propiciar, a rigor, a redução dos riscos, bem como contribuir para a competitividade desta empresa no mercado. Para avaliar a percepção do entrevistado quanto ao nível colaboração deste fornecedor, foi analisado o processo, por meio do qual o fornecedor envia as informações de tendências internacionais para a empresa $X$. Constatou-se de que o fornecedor colabora apenas de forma parcial com a empresa, ou seja, o mesmo providencia para a empresa $X$ o material de suporte para criação 


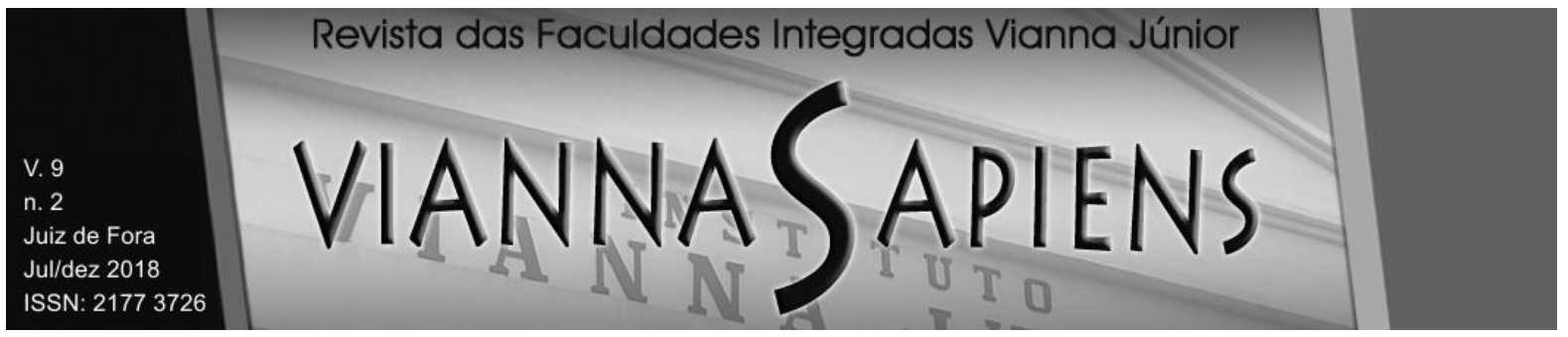

de tendências (revistas, catálogos com os lançamentos na Europa). Contudo, considerando a localização deste fornecedor, é possível afirmar que o mesmo possui acesso a um vasto conteúdo de moda que poderia ser retransmitido de forma mais acentuada à empresa X. Para Dyer e Singh (1998), isso representa uma fragilidade na construção de redes estratégicas e de vantagens competitivas.

À luz da revisão de textos de Gulati, Nohria e Zaheer; (2000) corrobora-se esta perspectiva, visto que, se o suporte do fornecedor fosse mais efetivo, poderia haver maior diluição de custos, bem como a ampliação do nível de confiança entre as partes. Este item foi explorado nas entrevistas realizadas, ao solicitar aos interlocutores expressarem o seu nível de confiança neste relacionamento. $O$ responsável pelo contato com o fornecedor informou que "...ocorre de maneira unilateral. Ou seja, apenas são recebidas as informações do fornecedor, sem que possamos demandar materiais específicos nem apontar as necessidades e percepções do mercado brasileiro."

Ao encontro dos textos de Barney e Hansen (1994), é possível afirmar que esse relacionamento de confiança evidenciou laços de média intensidade, através da inexistência de abertura para a troca de informações. Neste contexto, ao ser interrogado sobre o interesse em fomentar um contato contínuo com troca de informações e diálogo com o fornecedor, o entrevistado afirmou que o mesmo, desde o início das negociações, não teve interesse em realizar esta aproximação. Esta posição do fornecedor foi evidenciada, também, no processo de aprendizagem entre as partes, no qual não se verificou a existência de interesse na troca de informações mais detalhadas para fomentar e instrumentalizar o processo criativo.

Avaliando a outra entrevista realizada com o responsável pela área criativa verificou-se que o contato com o fornecedor é anual (uma vez por ano), por ocasião da qual ocorre uma interação de forma mais efetiva. Ao ser solicitado para descrever o processo colaborativo com este fornecedor para a criação de coleção, foi possível 


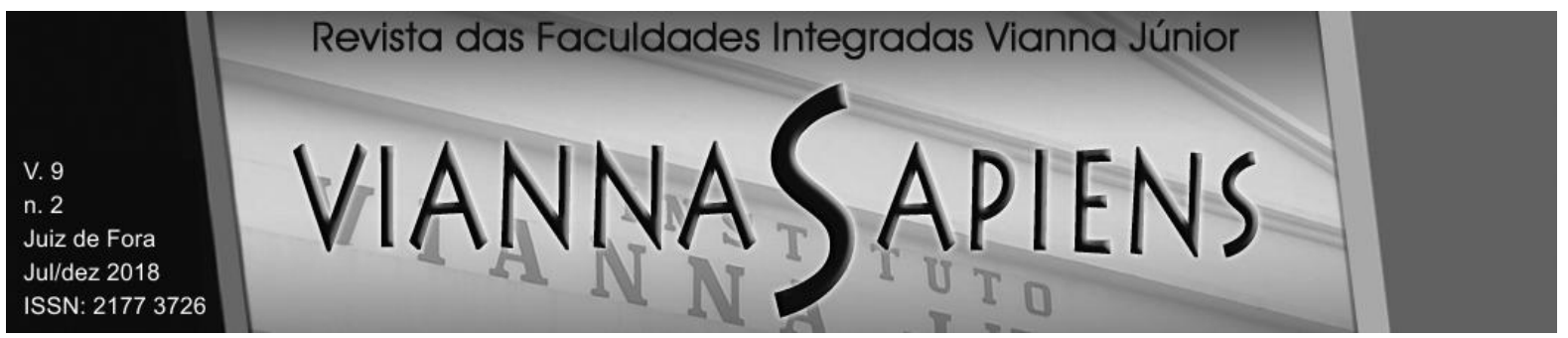

perceber a ausência de interesse do fornecedor em interagir de maneira mais constante. A entrevistada expressou que a empresa $X$ não possui uma relevância expressiva em relação a este fornecedor (de grande porte). Segundo Baum, Calabrase e Silverman (2000), para que a interação seja mais intensa as empresas necessitam ter portes similares. A entrevistada comentou que, em contrapartida, os clientes da empresa $X$ envolvem-se de forma muito mais ativa e intensa no processo de criação, por meio de fornecimento de dados e troca de informações, mesmo que estes clientes não utilizem toda a coleção produzida pela empresa $X$, aproveitando apenas o desenvolvimento de alguns itens específicos. Este posicionamento de clientes é retratado por Rousseau et al (1998), onde a partir da confiança e do amadurecimento do vínculo ocorre com base em um comportamento cooperativo.

Desta forma, pode-se afirmar que o processo de aprendizagem, no contexto da atuação profissional desta entrevistada, valida-se apenas na interação com os clientes, o que permite aprimoramento dos conceitos e inserção de novos elementos criativos neste processo. Lane e Lubatkin (1998) evidenciam esta dinâmica como uma das formas para obtenção do conhecimento.

Segundo a entrevista realizada com a proprietária da empresa $\mathrm{X}$, responsável pelo primeiro contato com este fornecedor, no ano 2004, a opção por este fornecedor ocorreu com base na sua experiência profissional anterior, em outra organização, na qual ela atuava e a qual percebia como uma referência no mundo da moda. A entrevistada deixou claro que este fornecedor sempre cumpriu com todas as cláusulas contratuais estabelecidas, desde o início da negociação. Alega que fatores culturais estão presentes, e uma característica em particular é a frieza e a rigidez com a qual este fornecedor cumpre com seus acordos. Isso, segundo ela, resulta em maior tranquilidade e segurança nas entregas e recebimentos de mercadorias. Contudo, na sua percepção, o fornecedor poderia ter uma maior proatividade no processo criativo, bem como poderia ser mais colaborativo, 


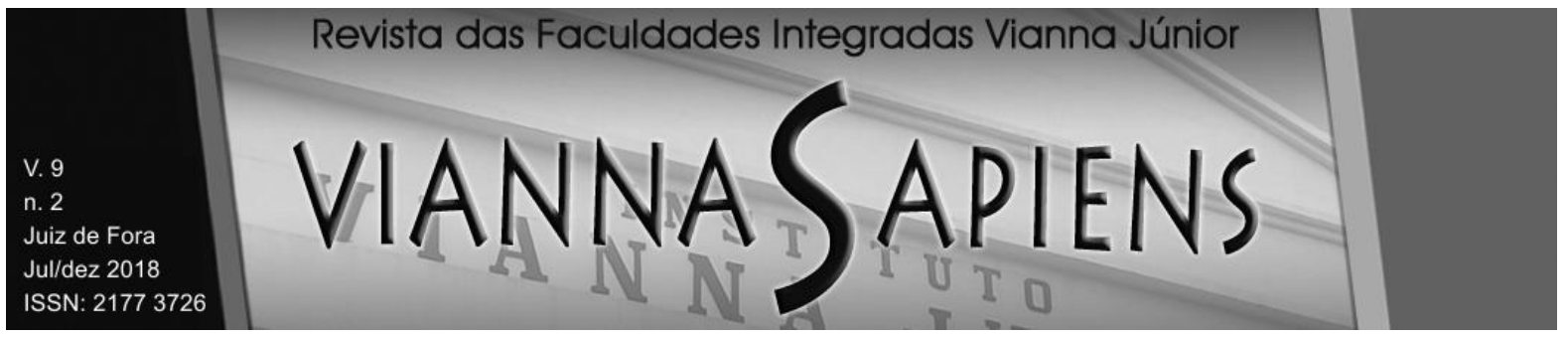

enviando as tendências internacionais com maior antecedência. Também destacou que esperava iniciativa do fornecedor para trocar informações do que é visto nas feiras e eventos locais. Como este processo não se concretizou, existe uma baixa sinergia subjacente à fluidez operacional conforme já comentado por Almeida, Silva e Júnior, (1998) que sinalizaram como um dos possíveis obstáculos para a consolidação das estratégias colaborativas.

Ao ser questionada acerca do processo de aprendizagem e possibilidade de novos negócios ou novas tecnologias, a entrevistada afirmou que este fornecedor, por ser muito conservador, impede uma maior aproximação, o que, por outro lado, resultou na redução da demanda. Comentou ainda, que um dos clientes da empresa $X$ finalizou as negociações com outra empresa, resultando em certa indisposição. A entrevistada relaciona esta situação com a falta de confiança técnica, já apontada por Nooteboom (2007).

No último ponto da entrevista, ao ser questionada sobre a possibilidade de ampliar os elos na área criativa, a entrevistada relata que existe muita desconfiança do fornecedor em estabelecer laços com a empresa para o processo criativo. Alguns fatores, que dificultam este tipo de relação são: as diferenças culturais, a distância geográfica entre as empresas envolvidas e a diferença de porte entre as empresas. Lane e Lubatkin (1998) apontam o status sine qua non, isto é, quanto maior a similaridade entre as empresas, maior será o processo de aprendizado, resultando em inovação. Contudo, a empresa $X$ efetuou a compra um equipamento com tecnologia de ponta, se diferenciando neste mercado, pois além da compra o fornecedor acompanhou o processo de instalação do equipamento e efetuou treinamento com os operadores da máquina. A parceria foi concretizada através de um longo contrato comprometendo ambas partes a manter sigilo absoluto neste processo. Além da empresa $X$, todos colaboradores que realizam o trabalho também assinaram se comprometeram com todos os termos estabelecidos. O local foi 


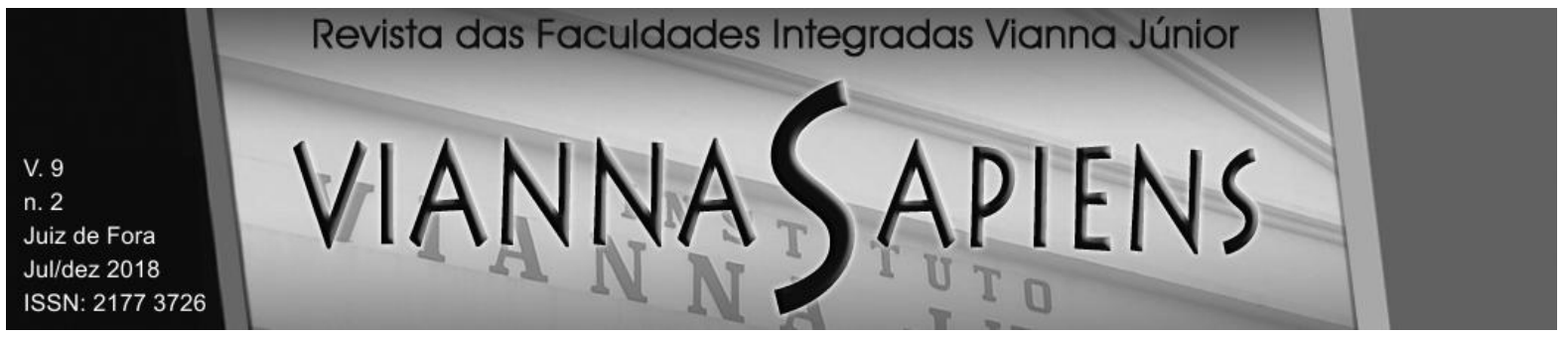

confinado com acesso mediante senha, assegurando maior confiabilidade entre as partes.

Avaliando o contexto dos entrevistados, as perguntas iniciais instigavam os respondentes a avaliar o fornecedor, sobre a postura colaborativa na troca de informações entre as partes. Para todos os entrevistados, o fornecedor demonstrou ser pouco colaborativo, na comparação com os estudos de Dyer e Singh, (1998). Identifica-se que a informação é recebida através do envio de materiais diretamente, sem o diálogo, trocas ou laços de proximidade, somente um envolvimento superficial.

Após a coleta de informações nestes setores, foi possível perceber que este fornecedor possui um envolvimento superficial com os entrevistados. Observa-se que mesmo nas duas áreas que possuem interface de contato, não é evidenciada maior proximidade com o fornecedor, de forma a propiciar o compartilhamento de informações que pudesse fundamentar uma demanda específica da realidade da empresa X no Brasil, possibilitando a customização ou adequação das tendências de moda internacionais. Não foi possível confirmar a existência, entre as partes envolvidas, de uma estratégia colaborativa, considerando que esta exige o enfoque à troca de informações, o que não foi evidenciado, no período observado, nas empresas em estudo. Da mesma forma, não foi evidenciado um estreitamento de laços com o objetivo de gerar o conhecimento e a qualidade no processo criativo, conforme apontado por Gulati, Nohria e Zaheer; (2000).

A sistemática de trabalho evidenciada in loco, consiste no recebimento de materiais novos (com acabamentos diferenciados) do fornecedor, pela área de criação, que realiza os testes físicos e de aderência, bem como a avaliação de aceitação do desenho pelos clientes. Após a área de criação coletar as informações dos clientes com o setor comercial, o novo material é analisado em conjunto (comercial e desenvolvimento). A equipe comercial escolhe os itens mais adequados 


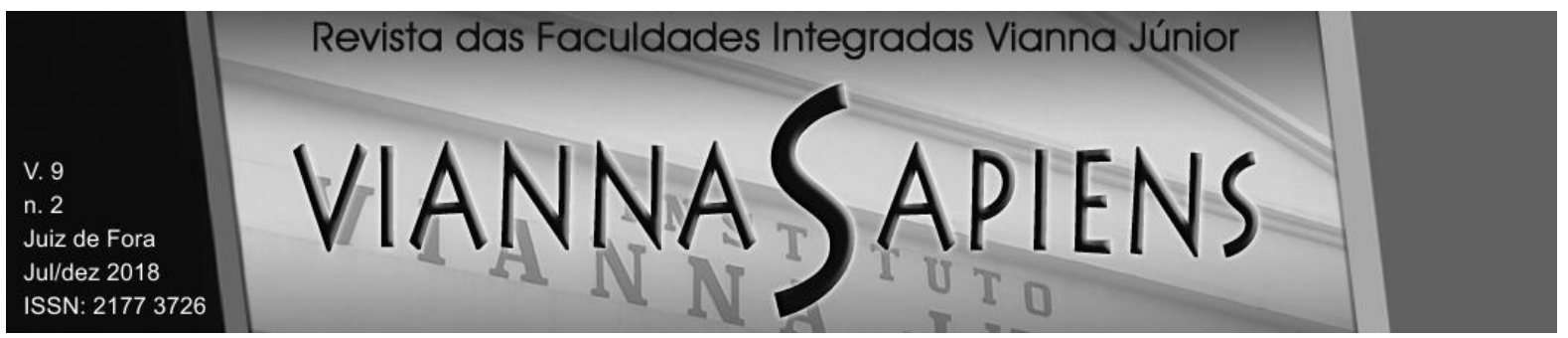

aos interesses dos seus clientes para importar do fornecedor uma quantidade adequada para a venda.

Não foi evidenciada, através da pesquisa, a utilização de diretrizes que orientam a forma de proceder ao licenciamento de tecnologia, produto ou marketing, pois não são elaborados acordos para a sua utilização pelas empresas envolvidas, conforme recomendam os autores Almeida, Silva e Júnior (1998). Esta realidade pode estar respaldada pelo fato de que os produtos entregues pelo fornecedor não são elaborados exclusivamente para a empresa $X$. No entanto, foi possível identificar uma antecipação da informação, quando se trata de produtos já gerenciados pela empresa X. Produtos de outros segmentos ou aqueles destinados para outras aplicabilidades não são apresentados nem informados pelo fornecedor para a empresa $X$.

Avaliando os laços de confiança todos os entrevistados foram questionados sobre o nível de confiança existente neste relacionamento. Avaliando o nível de confiança entre o fornecedor e a empresa $X$, evidenciou-se um processo muito bem parametrizado e identificou-se a existência de um relevante nível de confiança no funcionamento destes processos. Considerando que a confiança refere-se à expectativa de como as partes envolvidas agem e se comportam (de maneira confiável, previsível e justa, ou não) principalmente em situações em que possa ser identificado o oportunismo, percebeu-se que o fornecedor $\mathrm{X}$ age de forma previsível, conforme abordado por Woolthuis, Hillebrand e Nooteboom, (2005). O desenvolvimento do processo criativo - com base nos materiais e informações disponibilizadas pelo fornecedor à equipe de criação da empresa $X$ - é realizado através das visitas do fornecedor e do envio esporádico de material impresso.

Em alusão aos argumentos apresentados pelo Nooteboom (2007), em relação a edificação da confiança na relação entre as empresas, é possível afirmar que os níveis de confiança mudaram ao longo do tempo com o fornecedor, pois mesmo 


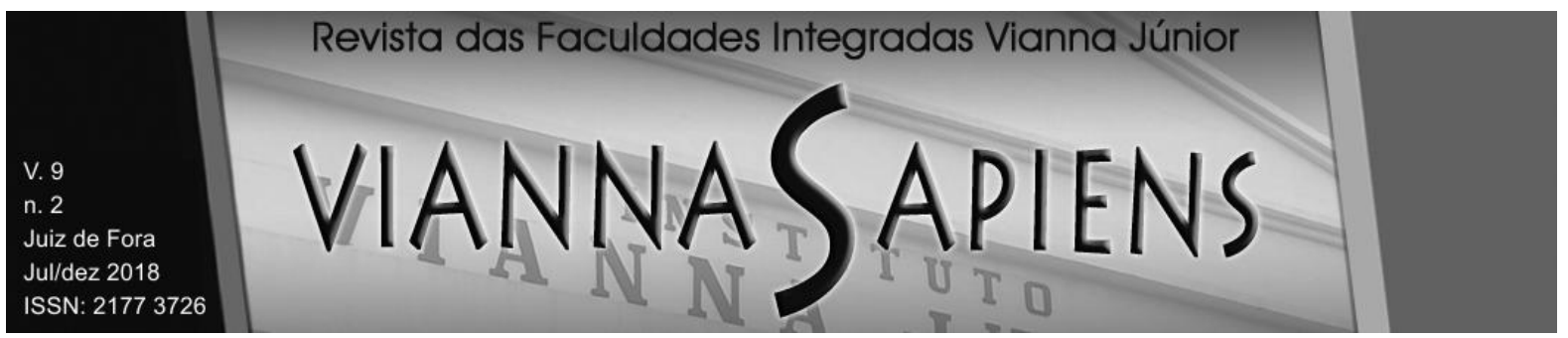

este sendo decorrente de um processo longo de negociação, o fornecedor mudou sua forma de venda, em função do quadro econômico da sua região. Ele reduziu sua equipe, bem como sua área de criação, culminando na redução da oferta de materiais desenvolvidos, o que foi sentido pela empresa $X$. Em contrapartida, a empresa $X$ estabeleceu relações com outros fornecedores, para suprir a sua necessidade com outros materiais para poder desenvolver as coleções demandadas por seus clientes.

Desta forma, a empresa $X$ apresentou produtos muito diferentes do que habitualmente vinha desenvolvendo, o que resultou em um distanciamento da equipe de criação do fornecedor em análise. A equipe optou por desenvolver novos conceitos e modelos oferecidas pelos novos fornecedores em outras bases e texturas, com o propósito de preservar a carteira de clientes da empresa sem prejuízo à qualidade no atendimento.

Ao perceber a redução da demanda por seus materiais, pela empresa $X, 0$ fornecedor realizou uma visita presencial na empresa, por ocasião da qual a direção da empresa $X$ apontou os aspectos frágeis da relação que se estabeleceu e as providências que tiveram de ser adotadas, para contornar a situação. Também foi colocada em cheque a confiabilidade das informações enviadas para a área de criação da empresa $X$, bem como o volume e a quantidades destas informações disponibilizadas pelo fornecedor, muito abaixo das expectativas (evidenciado pelos entrevistados, que sinalizaram que poderia ser realizada uma troca mais intensiva e ativa de informações, não somente envio de material impresso e físico).

Avaliando o processo de aprendizagem, Nonaka (1994) comenta que o conhecimento explícito representa o conhecimento transmitido formalmente, que, no caso em análise, é o material disponibilizado para a empresa $X$, sendo esta a forma de aprendizagem adotada na relação entre a equipe da empresa e o fornecedor no processo criativo. A aprendizagem baseada no conhecimento tácito foi utilizada para 


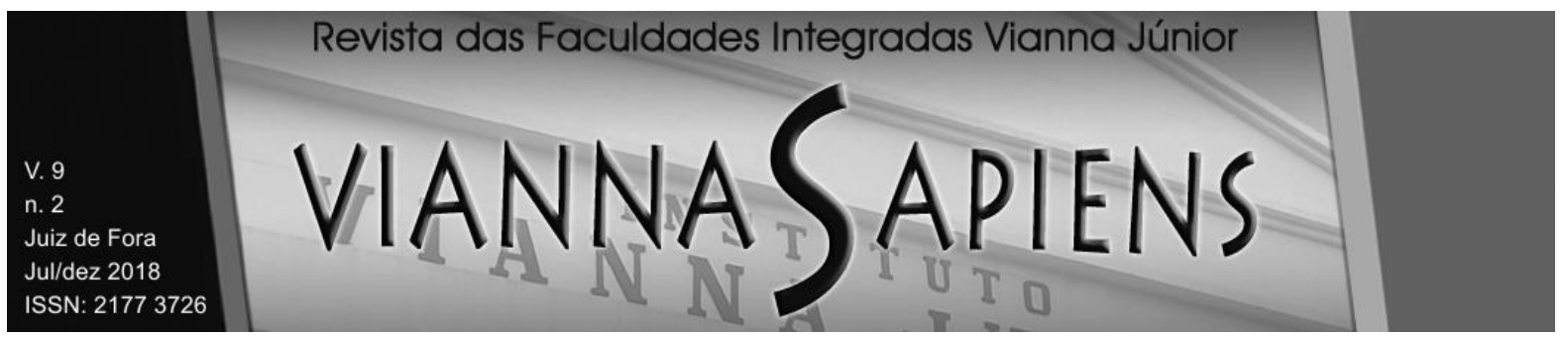

o processo de criação e desenvolvimento de coleção. De acordo com os entrevistados não foi percebido o conhecimento tácito, aquele que envolve ações de compartilhamento de conhecimento na relação pessoal com o fornecedor, pois não existe troca de informações e vínculo próximo com este. O fornecedor envia as informações de moda, tendências de forma antecipada, sendo que muitas destas informações já estão disponíveis no mercado internacional.

$\mathrm{Na}$ perspectiva de Nonaka (1994), o conhecimento pode emergir nas interações interorganizacionais, com a formação de alianças. Ao longo do estudo percebeu-se que o fornecedor forma aliança, mas formalmente, com escopo de trabalho definido, objeto e definição de restrições. Desta forma, se inviabiliza para a empresa $X$ realizar uma contrapartida de materiais que poderiam ser enviadas com enfoque nos interesses dela para realizar o desenvolvimento do processo criativo. A disseminação destes conhecimentos dentro do processo criativo ocorre por meio do recebimento do material, análise deste em reuniões, bem como a troca de informações com a área comercial.

Relacionando o exposto por Lane e Lubatkin (1998), por meio da análise de conteúdo das entrevistas realizadas, verificou-se que existe uma absorção de conhecimento entre empresa "professor" e "empresa aluno". A intensidade de troca de conhecimento ou aprendizagem, ocorre a partir das seguintes condições: o nível de abertura da "empresa professor", que no contexto estudado seria o fornecedor em repassar o conhecimento e a disponibilidade e abertura da empresa $X$ em absorver o conhecimento. O limitador desta negociação, de acordo com a coleta de dados e entrevistas efetuadas é a falta de interesse do fornecedor, visto que os profissionais envolvidos na relação, por parte da empresa $\mathrm{X}$, possuem interesse em ampliar e aproximar-se para realizar a troca de informações, o que poderia resultar na ampliação da aprendizagem do fornecedor e da empresa X. Não é identificada ainda uma prática de benchmarking, nem no compartilhamento do conhecimento 


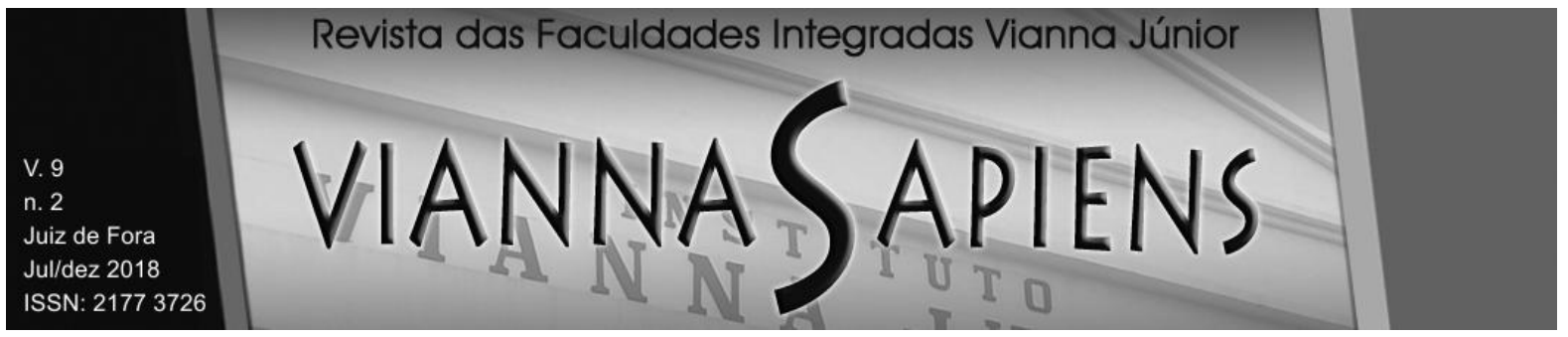

tácito (know-how; know-why) o que acarretaria em uma geração de valor percebido e estreitamento dos elos de ambas e vantagem competitiva no mercado.

Contudo, quando a empresa $\mathrm{X}$ e este fornecedor viabilizaram via contrato a compra de um equipamento com tecnologia de ponta, houve abertura e troca de conhecimento tático e explicito. Houve uma atenção e acompanhamento deste fornecedor assegurando que todo o processo de instalação ocorresse de maneira correta bem como a preocupação de todos os colaboradores envolvidos fizerem o produto corretamente.

Observado ainda a preocupação constante de confidencialidade das partes através de instrumentos contratuais, confinamento do equipamento e treinamento do fornecedor direto com os colaboradores envolvidos.

\section{CONSIDERAÇÕES FINAIS}

Ao explorar as estratégias colaborativas utilizadas na área criativa, percebese poucos estudos sobre o tema, pois a indústria criativa no Brasil é recente. De acordo com o FIRJAN o mercado criativo de 2004 a 2013 cresceu $90 \%$, duplicando o número de trabalhadores formais na área.

Ao pesquisar as especificidades da relação entre a empresa $X$ e um dos seus fornecedores, localizado na Itália, foi possível evidenciar as fragilidades da estratégia colaborativa, formalizada entre as duas organizações, no âmbito do processo criativo no segmento de moda e design. Constatou-se que as falhas na interação (laços fracos) contribuíram para tornar precário o processo de criação e de desenvolvimento de novos modelos, bem como obrigou a empresa brasileira a buscar novos fornecedores, que pudessem atendê-la, para não prejudicar o atendimento a seus clientes. 


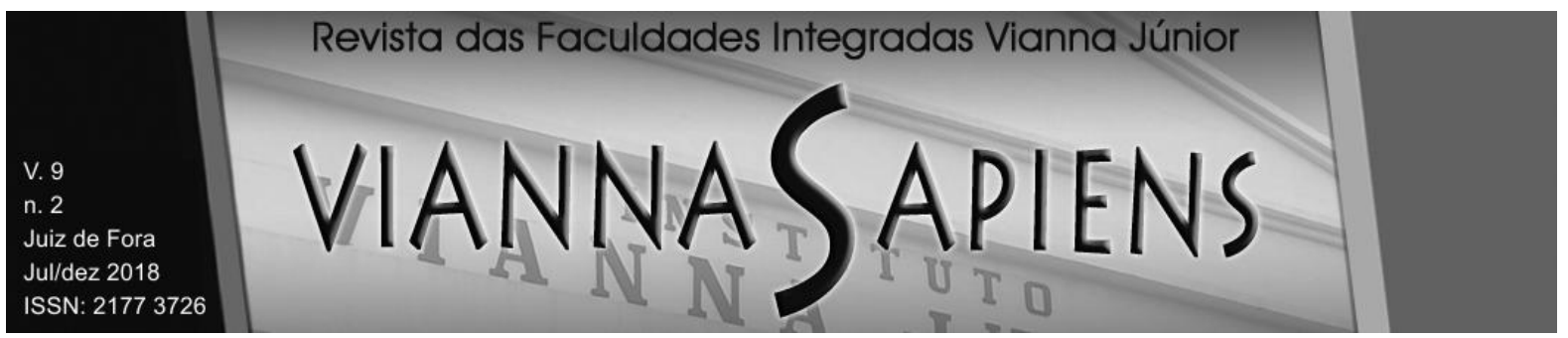

Os três gestores da empresa brasileira, entrevistados ao longo da pesquisa, detalharam os prejuízos decorrentes da falta de interação e do desinteresse da empresa italiana na relação. Foram unânimes em afirmar, que, considerando o local onde este fornecedor está inserido, o volume e tipo de informações disponibilizadas estavam muito aquém de suas possibilidades e das expectativas de seus parceiros no Brasil. Além disso, destacaram que várias informações do mercado brasileiro poderiam ser disponibilizadas para o fornecedor italiano, contribuindo para 0 processo de desenvolvimento de novos materiais, que poderiam, inclusive, ser oferecidos em outros mercados, o que aumentaria a proximidade e a confiança desta parceria.

Outro ponto que poderia ser melhor aproveitado é a troca de conhecimento, know-how e know-why oportunizando e aprimorando os processos. Nesta abordagem a empresa $X$ poderia ampliar suas estratégias colaborativas através da ampliação de elos de confiança com os fornecedores atuais, para desta forma obter resultados relevantes, com menor investimento alocado. Nota-se que os envolvidos neste processo possuem experiência no processo criativo e seria desejável estimular a celebração de parcerias colaborativas, para obter maior margem de lucro. Pode ser uma longa caminhada para chegar no modelo ideal mas, existindo maior confiança entre as partes podem surgir diversas oportunidades no mercado de moda e design, principalmente novas tecnologias e inovação no processo de criação.

Conclui-se que as principais contribuições do estudo foram de apresentar que é possível para as empresas de pequeno e médio porte estabelecer parcerias com empresas internacionais, cultivar no ambiente organizacional a importância de estabelecer estratégias colaborativas visando ampliação de lucrativa e diferenciação de mercado. 


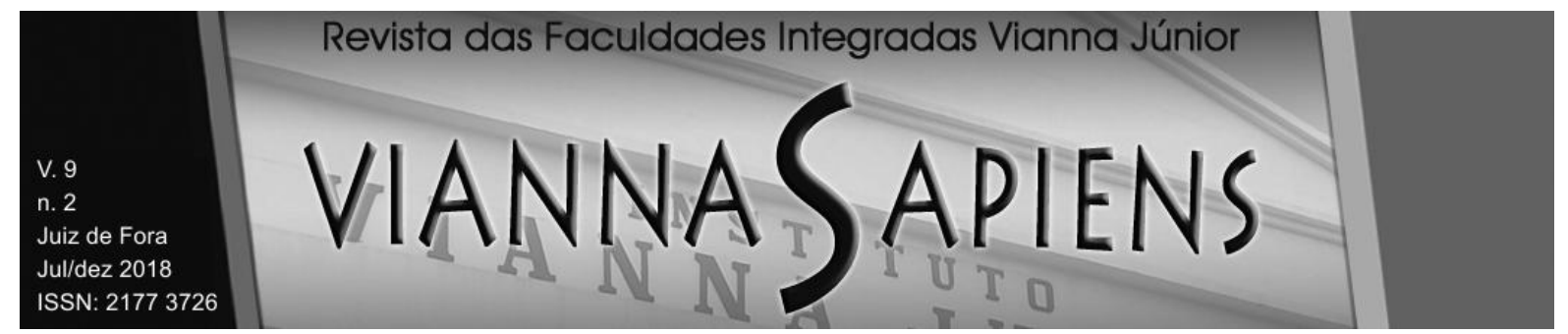

Para estudos futuros, a fim de sanar as limitações encontradas para realização deste artigo, sugere-se uma entrevista direta com o fornecedor italiano, a aplicação desta pesquisa em outras empresas que possuam estratégias colaborativas implantadas.

\section{REFERÊNCIAS}

AHUJA, G. The Duality of Collaboration: Inducements and Opportunities in the Formation of Interfirm Linkages. Strategic Management Journal [S.I.], v. 21, n. 3, p. 317, 2000.

ALMEIDA, Leandro Cabral de; SILVA, Jorge Ferreira da; JUNIOR, Ruy Bonates de Almeida. Alianças Estratégicas e a Indústria Financeira Brasileira: Impactos das Estratégias Colaborativas e Competitivas no Desempenho dos Bancos Comerciais, Múltiplos e de Investimento. ANPAD, 1998.

BARNEY Jay B., HANSEN Mark H. Trustworthiness as a Source of Competitive Advantage. Strategic Management Journal, Vol. 15, Special Issue: Competitive Organizational Behavior, (Winter, 1994), pp. 175-190

BAUM, J. A. C.; CALABRESE, T.; SILVERMAN, B. S. Don't Go It Alone: Alliance Network Composition and Startups' Performance in Canadian Biotechnology. Strategic Management Journal, v. 21, n. 3, p. 267, 2000.

COHEN, W. M.; LEVINTHAL, D. A. Absorptive Capacity: a new perspective on learning and innovation. Administrative Science Quarterly. v. 35, n. 1, p. 128-152, 1990 


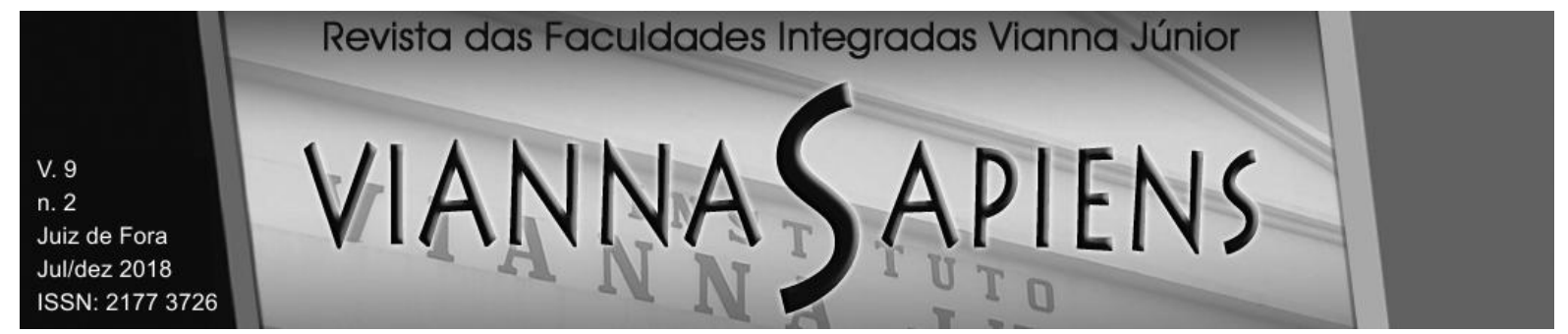

DYER, J. H.; SINGH, H. The Relational View: Cooperative Strategy and Sources of Interorganizational Competitive Advantage. The Academy of Management Review, v. 23, n. 4,1998

FIRJAN. Número de trabalhadores criativos cresceu $90 \%$ nos últimos dez anos http://www.firjan.org.br/economiacriativa/pages/release.aspx.Rio, 11 de dezembro de 2014 Acesso em 27 de Janeiro de 2015.

GIL, Antônio Carlos. Como elaborar projetos de pesquisa. 3. ed. São Paulo, SP: Atlas, 1996. 159 p.

GULATI, R.; NOHRIA, N.; ZAHEER, A. Strategic Networks. Strategic Management Journal, v. 21, n. 3, p. 203, 2000.

LANE, P. J.; LUBATKIN, M. Relative absorptive capacity and interorganizational learning. Strategic Management Journal [S.I.], v. 19, n. 5, p. 461, 1998.

LIRA, W. S. et al. Alianças estratégicas para o desenvolvimento sustentável.

Sociedade \& Natureza [S.I.], v. 19, p. 217-232, 2007.

NONAKA, I. A Dynamic Theory of Organizational Knowledge Creation. Organization Science, v. 5, n. 1, p. 14-37, 1994.

NOOTEBOOM, B. Social capital, institutions and trust. Review of Social Economy [S.I.], v. 65, n. 1, p. 29-53, 2007.

ROUSSEAU, D. et al. Not so different after all: a cross-discipline view of trust. Academy of Management Review [S.I.], v. 23, n. 3, p. 393-404, 1998. 


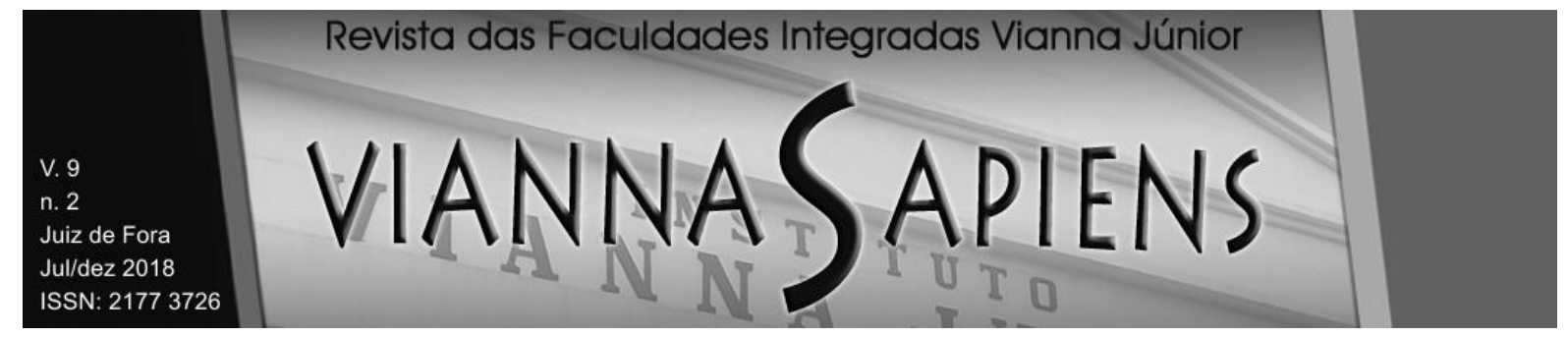

SILVA, Jorge Ferreira da; MOTTA, Paulo Cesar; COSTA, Lenise Saraiva de Vasconcelos. O Coalinhamento entre as Estratégias Competitivas e Colaborativas como Forma de Influenciar o Ambiente e Melhorar o Desempenho de Empresas. III Encontro de Estudos em Estratégia. SP de 09 á 11 de maio de 2007.

WOOLTHUIS, Rosalinde Klein, HILLEBRAND Bas and NOOTEBOOM Bart. Trust, Contract and Relationship Development . in: "The Oxford Handbook of Interorganizational relations" Cropper, Ebers, Huxham e Smith Ring. Organization Studies 2005 26: 813 European Group for Organizational Studies.May 25, 2005. 29p.

YIN; Robert K. Estudo de caso: planejamento e métodos. Trad. Daniel Grassi. 3. ed. Bookman. 2005. 212p.

ZAHEER, A.; VENKATRAMAN, N. Relational governance as an interorganizational strategy: an empirical test of the role of trust in economic exchange. Strategic Management Journal [S.I.], v. 16, n. 5, p. 373-392, 1995.

ZAHEER, A. et al. Does trust matter? exploring the effects of interorganizational and interpersonal trust on performance. Organization Science [S.I.], v. 9, n. 2, p. 141$159,1998$.

Recebido em 26/06/2018

Publicado em 21/12/2018 